\title{
INMIGRACIÓN Y EL DERECHO DE GENTES DE JOHN RAWLS. ARGUMENTOS A FAVOR DE UN DERECHO A MOVIMIENTO SIN FRONTERAS ${ }^{*}$
}

\author{
Immigration and John Rawls' Law of Peoples: Arguments \\ for a Right to Mobility without Borders
}

\author{
DANIEL LOEWE \\ Research Centre for Political Philosophy \\ Eberhard-Karls Universität Tübingen
}

\begin{abstract}
RESUMEN
Siguiendo una interpretación cosmopolita de la teoría de justicia de Rawls el artículo propone una concepción de igualdad de oportunidades global y, como parte de ésta, un derecho a movimiento sin fronteras (MSF). De acuerdo a esta investigación los argumentos que Rawls articula tanto en su teoría de justicia doméstica como en su teoría de relaciones internacionales contra la idea de la justicia global y contra un derecho a inmigración no son convincentes, y una interpretación coherente de su teoría no se opone a un derecho a MSF.
\end{abstract}

Palabras clave: igualdad de oportunidades, liberalismo igualitario, teorías de justicia, movimiento sin fronteras, derecho de gentes.

\begin{abstract}
According to a cosmopolitan interpretation of Rawls's theory of justice this article proposes a global conception of equality of opportunities and, as part of it, a right to mobility without borders (MWB). The research presented below shows that Rawls's arguments against the idea of global justice and a right to immigrate articulated both in his domestic theory of justice and his theory of international relations are not convincing and do not speak against a right of $M W B$.
\end{abstract}

Key words: equality of opportunities, egalitarian liberalism, theories of justice, movement without borders, law of peoples.

\section{INTRODUCCIÓN}

Aunque el fenómeno de la migración juega un rol importante y sin duda creciente en la política y cultura pública de muchas sociedades, casi no encontramos tratamientos

* Una versión de este texto fue discutida en febrero del 2007 en el coloquio del grupo de trabajo "Políticas Migratorias, Justicia y Ciudadanía", dirigido por el Dr. Juan Carlos Velasco en el Consejo Superior de Investigaciones Científicas en Madrid (CSIC). Aprovecho para agradecer a los participantes en el coloquio, así como a los directores de los grupos de trabajo acerca de las migraciones, Dr. Juan Carlos Velasco y Dr. José María González por la gentil invitación. 
sistemáticos de este fenómeno dentro de la filosofía política actual. La razón de esta desatención no es un simple descuido o una indebida apreciación de la relevancia de un fenómeno. Más bien, frente al fenómeno de la migración encontramos lo que podríamos denominar una suerte de desconcierto normativo: gran parte de las teorías filosóficas políticas normativas no ofrece en relación a esta directrices que se orienten de acuerdo a principios de justicia. En mi opinión, este desconcierto normativo se deja retrotraer en buena medida a la suposición teórica ampliamente aceptada -a menudo en forma tácita- en la filosofía política actual, que la justicia encuentra su campo de acción primario dentro de sociedades organizadas estatalmente. La relación entre diferentes sociedades, y entre éstas e individuos que no son sus ciudadanos, ${ }^{1}$ o bien se obvia o se considera como un tema derivado que ha de ser tratado en una etapa posterior al establecimiento de los principios de la justicia.

La teoría de justicia de Rawls es un ejemplo paradigmático de una teoría que acepta esta premisa como un punto de partida incuestionable. En este texto voy a examinar esta premisa de un modo crítico. En mi opinión, si aceptamos las intuiciones a la base de las teorías liberales igualitarias, especialmente la intuición a la base de la teoría de Rawls, hay pocas razones convincentes para limitar el alcance de los principios de la justicia de este modo. En vez de esto, los principios definitorios de la justicia deberían tener un alcance global. Si este es el caso, no habría razones de principio para limitar la migración en el contexto de la teoría de justicia de Rawls.

Para mostrar esto procederé en cinco pasos. (1) En primer lugar daré cuenta someramente del ideal de la igualdad de oportunidades (a continuación: IO) y de cómo el movimiento sin fronteras avanza este ideal. (2) En segundo lugar examinaré en qué medida la intuición fundamental de Rawls en el caso de la justicia doméstica nos debería llevar a aceptar principios de justicia global y, como parte de éstos, un derecho a movimiento sin fronteras (a continuación: MSF). (3) En tercer lugar me referiré a la teoría de las relaciones internacionales articulada por Rawls en The Law of Peoples y a su rechazo de la justicia global. (4) En cuarto lugar consideraré doce argumentos contra un derecho a MSF, que se pueden articular desde la perspectiva de su teoría de justicia doméstica y de justicia internacional. Esta sección constituye el foco principal de esta investigación. (5) El resultado de esta investigación es que en el contexto de la teoría de Rawls es posible articular argumentos coherentes para sostener una posición más favorable a la migración que la que él efectivamente sostiene. Ya que no hay razones para suponer que la cantidad de migrantes en nuestro mundo disminuirá en un futuro mediato, esta temática adquiere una relevancia que va más allá de un interés puramente teórico. En este texto daré por sentado un conocimiento general de la teoría de Rawls.

1 Un tema de una importancia por lo demás ampliamente reconocida, tanto por las teorías de relaciones internacionales que se basan en las tradiciones del derecho natural, como lo hace Grotius en De Iure Belli ac Pacis, como por teorías normativas de corte cosmopolita, como Kant en Paz Perpetua. 


\section{TEORÍAS DE JUSTICIA Y EL DERECHO A MOVIMIENTO SIN FRONTERAS (MSF)}

Como es conocido, la emigración es reconocida en nuestro mundo como un derecho humano. La Declaración Universal de los Derechos Humanos afirma que: "every one has the right to leave any country, including his own, and to return to his country" (Artículo 13-2). Como también es conocido, este derecho humano no implica un derecho a inmigración o una obligación de parte de otras naciones a las de origen a aceptar el ingreso de estos “emigrantes". Recurriendo a Walzer (Walzer, 1983: 40), uno de los pocos filósofos políticos que trata el tema de la inmigración con alguna extensión y profundidad, podemos denominar esta posición: la tesis de la asimetría entre la inmigración y la emigración.

Posiblemente, con la excepción de algunos activistas y personas activas en organizaciones humanitarias (que se concentran sobre todo, y por razones entendibles, en el tema de los refugiados), así como de unos pocos economistas liberales y muy pocos filósofos políticos, la tesis de la asimetría es ampliamente aceptada en nuestro mundo. No parece haber razones para afirmar que hay una obligación de justicia para aceptar inmigrantes potenciales, sobre todo cuando no se los considera como refugiados. Sin embargo, no es evidente que desde una perspectiva normativa liberal (y no desde una perspectiva económica o relativa a la sustentabilidad política de esta idea en nuestro mundo, perspectivas que no consideraré en este texto) dispongamos de argumentos que nos permitan sostener esta tesis, y correspondientemente cerrar las fronteras de nuestras sociedades. Por el contrario, y como sostendré en este texto, desde la perspectiva de una concepción normativa liberal hay buenas razones para defender el movimiento libre de personas a través de fronteras. Esta idea se expresa con un derecho a MSF, que de acuerdo a mi interpretación debería adquirir el estatus de un derecho humano.

La tesis de la asimetría no está carente de problemas. Se suele afirmar que es lógicamente absurdo afirmar un derecho a emigración sin un derecho complementario a inmigración, a menos que existan efectivamente, como a mediados del siglo XIX, un número considerable de estados que permitan la entrada libre (Dummett, 1992: 173). Pero aunque no compartamos la tesis acerca del supuesto déficit lógico de la asimetría, quedan todavía los problemas relativos al valor de un derecho a emigrar sin una obligación correspondiente a aceptar su ingreso. En este texto no me referiré a estas problemáticas. El tipo de problemas a los que me referiré en este texto surge una vez que aceptamos la independencia normativa en la definición de lo que es justo. A diferencia de teorías comunitaristas, teorías liberales igualitarias como la de Rawls, ${ }^{2}$ reconocen que los contextos culturales o políticos no determinan el concepto de lo justo. ${ }^{3} \mathrm{Si}$ aceptamos que los principios de justicia son normativamente

2 Hay razones para sostener que con la reformulación de su teoría en Political Liberalism (1993) y el fuerte acento dado en ésta al carácter "político" del liberalismo, así como en razón de la importancia otorgada al así llamado "consenso traslapado" en la metodología de justificación, Rawls debilita el carácter normativo independiente del liberalismo, recurriendo en su lugar a entendimientos compartidos dentro de las sociedades democráticas liberales. En este texto no me referiré a esta discusión.

3 Por cierto es posible defender valores liberales desde una perspectiva comunitarista, sosteniendo que la validez de éstos depende del contexto histórico. Esta es la posición de Walzer (1983), Gray (2000) y ejemplarmente Rorty (1998). Sin embargo, esta defensa comunitarista del liberalismo es débil y contradictoria: ella no puede dar cuenta del carácter eminentemente universal de las libertades y derechos liberales. 
independientes, y reconocemos el valor de un derecho a movilidad dentro de las fronteras políticas de una sociedad: ¿en base a qué razones de principio podemos restringir la aplicación de los principios de justicia a los espacios circunscritos por las fronteras políticas y correspondientemente limitar un derecho a MSF?

\section{Igualdad de oportunidades (IO)}

La IO ocupa un lugar central en las teorías liberales. Por cierto una concepción de IO no garantiza -pero tampoco implica- que todos los individuos vayan a tener un éxito igual en la realización de sus planes de vida. Concepciones liberales de IO son procedimentales y por tanto no son teorías que midan la justicia de acuerdo a los resultados. De un modo general es posible distinguir dos concepciones de IO: una formal y una material. Teorías liberales clásicas tienden a sostener una u otra versión de la primera, mientras que autores liberales igualitarios favorecen la segunda.

a. Concepción formal: de acuerdo a esta concepción, la IO aspira a garantizar que todos aquellos que tienen los atributos relevantes para cumplir con los requerimientos de una actividad determinada, tengan una oportunidad igual para competir por esa posición, independientemente de una serie de factores (ejemplarmente sexo y raza) que se consideran como irrelevantes (a menos, por cierto, que estos factores sean relevantes para cumplir con las exigencias de la actividad en cuestión, lo que debe ser demostrado en cada caso). Esta concepción de IO se suele denominar "principio de antidiscriminación".4

b. Concepción material: la segunda es una concepción más igualitaria de la IO. En la actualidad ella se ve reflejada en las obras más difundidas de la filosofía política. De acuerdo a esta concepción, el tener acceso a ventajas implica que debe haber IO no sólo para competir por las posiciones, sino que también, y primeramente, para adquirir las calificaciones necesarias para poder competir por éstas. El principio de igualdad de oportunidades implica un "antes" y un "después" (Roemer, 2000): antes que las oportunidades sean igualadas y después de esto, cuando el "campo de juego" de los individuos que compiten entre sí está diseñado de un modo tal que la competencia es justa. Para garantizar la IO se requiere por tanto una intervención más extensiva y en un momento más temprano, lo que implica la existencia de instituciones sociales que regulen las desventajas que surgen en razón de las arbitrariedades. A continuación me guiaré por esta concepción amplia de IO.

4 Este principio no debe ser confundido con la así llamada "meritocracia". Los dos principios tienden a ocupar el mismo espacio conceptual cuando los factores relevantes para acceder a una posición refieren exclusivamente a la excelencia (piense en el acceso a una compañía de baile o en una carrera de 100 metros planos). En estos casos se mide una capacidad natural plus training. Pero debido a diferentes razones -por ej., debido a que no todos los mercados son completamente competitivos- esto no es siempre así. Que el más calificado para una actividad determinada obtenga la plaza, como el principio de la meritocracia exige, es una exigencia diferente a la planteada por el principio de antidiscriminación, de acuerdo al cual, luego de descartar los factores considerados como irrelevantes, pueden todavía quedar una serie de elementos que pueden ser considerados por el empleador como relevantes, y que no refieren a la calificación. Y si el mercado en este caso no es completamente competitivo, hay menos incentivos por parte del empleador para que el más calificado obtenga siempre la plaza (compare Epstein, 1992; Cavanagh, 2002). 


\section{Igualdad de oportunidades global y MSF}

Defensores del liberalismo igualitario se esfuerzan por contrarrestar lo que Rawls ha denominado "la arbitrariedad de la fortuna" (Rawls, 1971: 102). Hay factores sobre los que los individuos no tienen control y que influencian, de un modo en ocasiones determinante, la posibilidad de los individuos de tener acceso a determinadas ventajas. Desde la perspectiva del liberalismo igualitario esto no es justo. El acceso a bienes deseados debe referir a características (morales) relevantes y no a arbitrariedades. La intuición básica del pensamiento liberal igualitario es que las desigualdades en la distribución total de posiciones sociales sólo pueden ser justificadas cuando hay mecanismos para contrarrestar aquello que hace que los resultados no sean justos. $\mathrm{O}$ dicho de un modo positivo: cuando hay IO. Yo sostengo que esta intuición debe tener un alcance global: si los principios liberales basados en esta intuición son normativamente independientes, no hay razones de principio para limitar su aplicación al espacio circunscrito por las fronteras políticas (compare Caney, 2001a, 2001b). De este modo, el ideal de la IO no remitiría exclusivamente a las oportunidades disponibles dentro de cada sociedad, como en el caso de la justicia doméstica. Este ideal tampoco remitiría exclusivamente a igualar las oportunidades entre las sociedades, de modo tal que las posiciones relevantes dentro de éstas sean conmensurables (medidas, por ej., de acuerdo a la calidad de vida) con las posiciones relevantes dentro de otras sociedades. Más allá de esto, y como explicitaré a continuación, es necesario sostener un derecho a MSF.

Teorías de justicia cosmopolitas sostienen que para avanzar el ideal de la IO se requieren principios de justicia global efectivos mediante instituciones con un alcance global. Yo sostengo que estas instituciones deben garantizar, junto a otros bienes a los que no me referiré en este texto (como, por ejemplo la garantía de ciertos recursos de acuerdo a algún principio de distribución global y de ciertas libertades fundamentales), una libertad individual fundamental de movilidad no sólo efectiva dentro de una sociedad determinada -como normalmente se asume-, sino que entre sociedades organizadas políticamente. Al garantizar esta libertad fundamental a movilidad, el derecho a MSF avanza el ideal de la IO de dos modos. Por una parte, en tanto el derecho a MSF torna efectiva la posibilidad de inmigrar, éste garantiza una nueva oportunidad en la realización de nuestros planes de vida. De este modo se igualan la desigualdades en oportunidades que surgen en nuestro mundo en razón de cuán privilegiada es nuestra ciudadanía al momento de emigrar. Por otra parte, en tanto la posibilidad de inmigrar está garantizada, los migrantes potenciales disponen de otras oportunidades para desarrollar sus planes de vida: aquellas que son efectivas en otras sociedades a las de origen (que por cierto sean compatibles con las demandas de los principios de la justicia). De este modo, si bien no es posible contrarrestar en forma completa la desigualdad en las oportunidades disponibles en las distintas sociedades, en tanto desaparecen los impedimentos legales para poder acceder a las oportunidades disponibles en otras sociedades, es posible avanzar en la dirección señalada por el ideal de la IO.

No todos los individuos harán uso de un derecho a MSF. Emigrar e inmigrar son partes de un proceso siempre difícil y a menudo doloroso (compare el sugerente estudio de 
Vitale 2004). Sin embargo, es previsible que con un derecho efectivo a MSF el número de personas que en busca de nuevas oportunidades cruza fronteras políticas aumente en forma considerable. Pero si desde la perspectiva de una teoría de justicia igualitaria lo que cuenta es el individuo y sus libertades, no hay razones para restringir la posibilidad de migrar de todos aquellos individuos que, por una razón u otra, están dispuestos a cargar con los costos vinculados, para así acceder a las oportunidades disponibles en otras sociedades. Si aceptamos que la IO es el elemento central en una teoría de justicia liberal igualitaria, no hay ningún elemento normativo relevante contra el MSF. Este es un mecanismo que nos permite avanzar en el desarrollo del ideal a la base de estas teorías: garantizar IO para todos los individuos.

\section{LA POSICIÓN ORIGINAL Y LOS PRINCIPIOS DE LA JUSTICIA}

La intuición básica de la teoría de justicia de Rawls -o como él lo expresa: un punto fijo de nuestros juicios bien meditados- es que nuestro punto de partida económico y social, así como nuestra dotación natural, son elementos "contingentes" y por tanto "moralmente arbitrarios" (arbitrary from a moral point of view). Estos últimos son el resultado de la lotería natural. Esto se extiende incluso a la posesión de un carácter superior que pudiese favorecer el desarrollo de capacidades productivas (Rawls, 1971: 104). Nadie puede afirmar que merece su dotación de talentos naturales o su posición económica y social inicial. "Mérito" presupone la existencia de un esquema de cooperación. Ya que la posición económica y social inicial, así como la dotación de talentos tiene consecuencias profundas en las oportunidades en la vida de los individuos, las instituciones más importantes de la sociedad deben ser organizadas de acuerdo a principios de justicia que regulen las consecuencias de estos factores contingentes. Sólo entonces es posible tener "expectativas legítimas".

De acuerdo a la tradición contractualista en la cual Rawls inscribe su teoría, estos principios de justicia son escogidos en una situación original que él denomina "posición original". La posición original está caracterizada por el así llamado "velo de ignorancia". Éste limita el conocimiento disponible al escoger los principios de la justicia. Las personas (en A Theory of Justice) o los representantes de ciudadanos (en la reformulación de Political Liberalism) no conocen ni su posición social ni su posición económica en la sociedad. Ellos tampoco conocen su dotación de talentos naturales. Por encima de esto, ellos no conocen su concepción particular del bien. Bajo estas restricciones informativas, las partes en la posición original no pueden favorecer principios que los aventajen particularmente. Por el contrario: al escoger principios que avancen sus intereses, escogen simultáneamente principios que avanzan los intereses de cualquier otro en esas circunstancias de elección. Esto corresponde a una situación de imparcialidad inicial, en la cual se han de escoger los principios de justicia, de acuerdo a los cuales deben ser organizadas las instituciones más importantes de la sociedad en la que estos individuos han de vivir. De acuerdo a Rawls, las partes en la posición original escogerían dos principios de la justicia. El primer principio establece que "cada persona tiene un derecho igual al sistema total de libertades básicas iguales más extensivo que sea compatible con un sistema similar de libertad para todos". 
El segundo principio tiene dos partes: las desigualdades sociales y económicas tienen que ser organizadas "(a) para el mayor beneficio de los menos aventajados, consistente con el principio de ahorro justo", y tienen que estar "(b) vinculadas a posiciones y cargos abiertos a todos en condiciones de igualdad equitativa (fair) de oportunidades" (Rawls, 1971: 302). La relación entre estos principios está regulada por un orden lexicográfico que impide sacrificar el primer principio a favor de ventajas económicas. De este modo pretende Rawls neutralizar los efectos de los factores contingentes y eliminar la arbitrariedad de los resultados.

\section{Otras contingencias: justicia global}

Uno de los puzzles más desconcertantes (desde la perspectiva de una explicación teórica y no histórica) en el pensamiento liberal contemporáneo refiere a la tensión entre una concepción normativa con una aspiración universal, y la expresión de estos estándares morales mediante principios de justicia válidos dentro de una sociedad cuyas fronteras son contingentes y arbitrarias. Para la mayoría de los autores liberales, aunque las fronteras son irrelevantes en la determinación de lo justo, ellas siguen ocupando un lugar central dentro de sus teorías al definir cuál es foco de la justicia. La teoría de Rawls es una teoría de justicia social, es decir, una teoría acerca de la justicia de las instituciones más importantes de una sociedad organizada estatalmente. ${ }^{5}$

Autores con una orientación cosmopolita han afirmado que la intuición básica de Rawls nos debe llevar más allá de las fronteras estatales en la realización de la justicia liberal (Beitz, 1979; Pogge, 1989; y Barry, 1974, 1989). De igual modo a como Rawls en el caso doméstico aspira a limitar mediante principios de justicia las consecuencias de los elementos arbitrarios en las oportunidades de los individuos, en el plano global también habría que limitar las consecuencias de los elementos contingentes mediante principios de justicia global. Estos elementos se extenderían más allá de los señalados por Rawls, y tendrían que incluir contingencias que tienen consecuencias profundas en las oportunidades de todos los individuos como la nacionalidad y la ciudadanía. Nadie puede ser hecho responsable por haber nacido en Sierra Leona, con una esperanza estadística de vida de 42 años, y no en Japón, con una esperanza estadística de vida de 78 años.

De acuerdo a Rawls la personalidad moral es una condición suficiente para ser sujeto de justicia. Esta es definida en relación a los dos poderes morales: (a) la capacidad de formar una concepción del bien propio, y (b) la capacidad del sentido de la justicia, esto es, el deseo de actuar de acuerdo a principios de justicia (Rawls, 1971: 505). Pero si todos aquellos que tienen estas capacidades son sujetos de justicia, no hay ninguna razón para suponer que debamos limitar nuestras obligaciones de justicia a los sujetos que casualmente viven en nuestra sociedad. Desde la perspectiva de una interpretación cosmopolita, una

5 La crítica al liberalismo que Tamir (1993) articula con referencia a la teoría de Rawls, de acuerdo a la cual el liberalismo sería eminentemente nacionalista, no da en el blanco: la teoría de justicia de Rawls, así como las teorías similares que se han articulado, son teorías acerca de instituciones estatales y no teorías acerca de naciones, y mucho menos en el sentido en el que Tamir, pero también otros en el debate, hace referencia a la nación, esto es, como una construcción eminentemente cultural. 
interpretación coherente de la teoría de Rawls tendría que tomar la forma de una teoría de justicia global.

Esto no quiere decir que en la posición original los individuos escogerían una estructura institucional global en la que no tengan cabida las diferentes sociedades. Hay buenas razones contra la idea de un Estado global. En mi opinión, ellas refieren sobre todo al peligro de una tiranía sin fronteras y al derecho liberal fundamental de salida. Otras razones relevantes refieren a lo que Höffe ha denominado un "derecho a diferencia" de los pueblos (Höffe, 1999). Yo no voy a entrar a este tema, sino que sólo indicaré que si estas razones son plausibles, los individuos en la posición original escogerían un orden institucional global que dé cabida a diferentes sociedades políticamente organizadas. Los principios de la justicia propuestos y defendidos por Rawls -incluyendo el segundo principio con la regulación de las desigualdades económicas- deberían encontrar su campo legítimo de acción no sólo dentro de las fronteras políticas de las sociedades organizadas en forma estatal, sino que entre estados, o entre individuos a través de las diferentes sociedades. Si aceptamos la intuición básica de Rawls, no parece haber razones para no extender el alcance de estos principios al contexto global.

\section{La interpretación cosmopolita y MSF}

Martha Nussbaum ha criticado que la interpretación cosmopolita de la teoría de Rawls es demasiado especulativa y por tanto inadecuada para determinar resultados concretos (Nussbaum, 2006). Sin embargo, esta crítica no es conclusiva. La interpretación cosmopolita es posiblemente tan especulativa como la interpretación doméstica. En la interpretación cosmopolita y en el caso doméstico estamos sujetos a las mismas limitaciones metodológicas: la posición original es un método para guiar nuestro raciocinio moral con respecto a temas puntuales uno después del otro. ${ }^{6}$ Con respecto al tema de la inmigración, esta interpretación ofrece guías prácticas para el esbozo institucional. A continuación argumentaré en este sentido.

De acuerdo a la estructura argumentativa de su teoría de justicia doméstica Rawls supone, (a) que las sociedades son sistemas cerrados, (b) que todos los individuos están bajo la jurisdicción de un Estado y (c) que los ciudadanos realizarán una vida completa dentro de las fronteras políticas de esta sociedad. Dicho de otro modo: al nivel de la teoría ideal la migración es un fenómeno desconocido. Pero las suposiciones de Rawls son difícilmente conciliables con la intuición básica de su teoría. Si la aspiración básica del liberalismo igualitario es avanzar en la realización del ideal de la $\mathrm{IO}$, no es entendible por qué habría que aceptar estas suposiciones.

Primero: como a menudo se argumenta, las sociedades políticas no son sistemas cerrados. La condición de autarquía es difícilmente sostenible (compare Beitz, 1979; Benhabib, 2004; Nussbaum, 2006). Sociedades están en interacción con otras sociedades y las oportunidades que ellas pueden ofrecer a sus ciudadanos o miembros dependen en un modo considerable de los términos de esta interacción.

6 Para una interesante elaboración de este punto -en relación a la utilización del aparato teórico de Rawls para justificar incluso derechos de animales no humanos- compare Rowlands, 1998, 2002. 
Segundo: la ciudadanía que adquirimos con nuestro nacimiento, ya sea de acuerdo a la de nuestros padres o a la otorgada por el lugar de nacimiento, es un elemento contingente: ella no depende de nosotros y tiene consecuencias mayores en nuestras oportunidades en la vida. En esta línea argumentativa afirma Carens que el estatus de la ciudadanía en las democracias liberales occidentales es el equivalente moderno del privilegio feudal: un estatus heredado que amplía nuestras oportunidades en la vida (Carens, 1987, 1992). En la posición original los individuos querrían protegerse ante la eventualidad de que su ciudadanía esté asociada con desventajas en relación a oportunidades relevantes.

Tercero: los planes de vida de los individuos, por cierto desconocidos dentro de la posición original, pueden ciertamente implicar el deseo de abandonar la sociedad de nuestro nacimiento. Ya que los individuos en la posición original tienen un interés superior en sus planes de vida, no hay razones para suponer que los individuos renuncien de antemano a esta oportunidad para desarrollar sus planes de vida.

De acuerdo a Rawls, al escoger los principios de la justicia los individuos deben atender a la posición de las personas representativas peor situadas. Dicho de otro modo, ellos deben escoger de acuerdo al criterio Maximin que asegura el máximo de los mínimos posibles. Si este es el caso, los individuos tendrían que atender a la posibilidad de que sus sociedades, ya sea debido a los términos de interacción entre las distintas sociedades o a factores internos a éstas, como, por ejemplo, mala gestión o carencia de recursos naturales ocupen una posición desaventajada, y por lo tanto se disponga en éstas de oportunidades extremadamente restringidas para desarrollar los propios planes de vida. Por encima de esto, los individuos tendrían que atender a la posibilidad que la realización de sus planes de vida sea difícil realizar en la sociedad en la que casualmente nacieron: quizás hay pocos individuos que comparten esa concepción del bien, lo que torna difícil su realización (por ejemplo una religión o Weltanschauung); o quizás las oportunidades relevantes para realizar la propia concepción del bien se encuentran en otras sociedades (por ejemplo una carrera en la empresa discográfica no es igualmente realizable en cualquier sociedad); o quizás la oportunidad para desarrollar una vida emocional estable exige cruzar fronteras (el amor no las conoce). Ya que es ciertamente posible que la realización de nuestros planes de vida implique la necesidad de cruzar fronteras, los individuos en la posición original escogerían que los principios de justicia tuviesen algún tipo de aplicación global, y como parte de la expresión institucional de estos principios escogerían un derecho a MSF.

\section{3. ¿MSF o principios de justicia distributivos?}

¿No bastaría con afirmar que la interpretación cosmopolita justifica principios distributivos entre estados, o incluso principios distributivos entre individuos a través de las fronteras estatales, pero no un derecho a migración? Después de todo, si mediante principios distributivos globales se garantizan un conjunto similar de oportunidades en las diferentes sociedades, ¿no estaría ya garantizada la $\mathrm{IO}$, lo que tornaría un derecho a inmigración innecesario? Desde esta perspectiva, la defensa de principios de justicia global no implicaría una defensa del MSF. Aunque esta tesis parece ser sustentada por el hecho de que entre los defensores de teorías de justicia global no encontramos posiciones claras con respecto a la inmigración, ella no es convincente. 
Primero: aunque fuese el caso que los principios de justicia distributiva global fuesen efectivos, no sería de esperar que el conjunto de oportunidades en las diferentes sociedades fuese similar. Algunas sociedades continuarían siendo considerablemente más exitosas que otras. De este modo, los individuos continuarían sufriendo desventajas en razón de contingencias moralmente arbitrarias.

Segundo: la prioridad de la libertad que Rawls afirma con su principio lexicográfico, torna imposible, en una interpretación cosmopolita, limitar la libertad de los individuos para inmigrar a otras sociedades. Como vimos, las razones para emigrar pueden ser variadas. Aunque las oportunidades en las diferentes sociedades fuesen numérica y cualitativamente comparables en razón de principios de justicia global efectivos, no se sigue que se pueda limitar la libertad de los individuos para perseguir su concepción del bien. Y esta libertad incluye el MSF.

\section{EL DERECHO DE GENTES DE RAWLS}

Primero en su artículo "The Law of Peoples", y luego en forma más elaborada en su monografía con el mismo título (1999) realiza Rawls una extensión de su concepción de justicia liberal doméstica al contexto de las relaciones entre pueblos. Como es conocido, Rawls rechaza no sólo la interpretación cosmopolita de su teoría, sino que también la alternativa cosmopolita en cuanto tal. Su teoría no sería una teoría de justicia global, en la que, como en la interpretación cosmopolita, los individuos están en el centro de la justificación de los principios de justicia. Ella es una teoría acerca del derecho de los pueblos, es decir: una teoría normativa sobre las relaciones entre los pueblos. De acuerdo a Rawls, los principios de justicia de su teoría, concebidos para el caso doméstico, no encontrarían ningún campo de aplicación en el plano internacional. Mucho ha sido dicho acerca de esta extensión y sus problemas (Pogge, 1994; Buchanan, 2000; Beitz, 2000; Tasioulas, 2002; Tan, 2000, 2004; Moellendorf, 2002; Benhabib, 2004; Martin/Reidy, 2006). A continuación me referiré someramente al Derecho de Gentes de Rawls, para posteriormente referirme a las consecuencias de esta extensión para el tema en atención.

En forma analógica a la posición original en la teoría de justicia doméstica, Rawls imagina en la primera parte de la teoría ideal del Derecho de Gentes una segunda posición original, en la cual los representantes de pueblos liberales deben tomar una decisión acerca de los principios reguladores de las demandas entre pueblos. Siguiendo en forma analógica la tesis central en la teoría doméstica sobre la igualdad moral entre individuos (Rawls, 1999: 41), él propone que en razón de la igualdad entre los pueblos, los representantes de pueblos liberales estarían de acuerdo con ocho principios (Rawls, 1999: 37). Estos expresarían una concepción justa y razonable para el orden internacional. La independencia y igualdad de los pueblos está expresada en los principios (1) y (3); la obligación de cumplir tratados está expresada en el (2), la no-intervención está expresada en el (4), el derecho a autodefensa en el (5) las reglas de ius in bello están expresadas en el (7). El principio (6) establece que los pueblos tienen que respetar los derechos humanos (Rawls tiene una concepción más bien limitada acerca de estos), y el principio (8) establece una obligación de asistencia. 
Rawls aspira a que su teoría tenga una aceptación más amplia que la asegurada por los pueblos liberales que se declaran de acuerdo con estos principios. Por eso, en la segunda parte de la teoría ideal él se pregunta si otro tipo de sociedades, que no son liberales, estaría de acuerdo con estos principios. Para esto él elabora una tercera posición original, en la cual los representantes de las así llamadas sociedades jerárquicas decentes (a continuación: SJD) tienen que decidir si aceptan estos principios.

SJD son definidas en base a tres características (Rawls, 1999, 64-5): (a) ellas no son agresivas, (b) se organizan de acuerdo a una concepción del bien, y (c) tienen una jerarquía de consultación. SJD no son liberales: sociedades liberales no se pueden organizar de acuerdo a una concepción de bien, y deben honrar principios democráticos (y no sólo de consultación). Rawls piensa que estas sociedades estarían de acuerdo con la lista de principios escogidos por los pueblos liberales. De este modo ellas serían miembros regulares con los mismos derechos del Derecho de Gentes (Rawls, 1999: 59). Es por esto que él denomina sociedades bien-ordenadas a los pueblos liberales y a las SJD. El Derecho de Gentes de Rawls, que él caracteriza como una utopía realizable, será realizado, cuando todas las sociedades del mundo sean bien-ordenadas.

Pero en nuestro mundo con sus muchos males, una teoría del Derecho de Gentes debe ofrecer directrices de acción (Rawls, 1999: 89). Esto lo realiza Rawls en la parte no-ideal de su teoría. Rawls refiere aquí a tres tipos de sociedades. Por una parte tenemos los así denominados "estados fuera de la ley", que no reconocen los principios del Derecho de Gentes (Rawls, 1999: 90). Ellos son agresivos y no respetan los derechos humanos de sus miembros. Por otra parte tenemos "sociedades cargadas". Estas son sociedades que en razón de sus condiciones poco favorables no pueden organizarse en forma liberal o decente. Un tercer tipo de sociedad son los absolutismos benévolos. Estos no son ni agresivos ni democráticos, pero respetan los derechos humanos fundamentales de sus miembros. De acuerdo a Rawls, el Derecho de Gentes debe ofrecer mecanismos para que las sociedades bien-ordenadas se protejan de los estados fuera de la ley y los lleven a realizar reformas, y para que éstas asistan a las sociedades cargadas de modo que lleguen a ser sociedades bien-ordenadas.

El Derecho de Gentes de Rawls muestra una desatención particular por el caso de la migración. Esta desatención se puede retrotraer al hecho de que, de acuerdo a su teoría, la migración no es un fenómeno que requiera la aplicación de criterios o principios de justicia. Rawls menciona el fenómeno de la inmigración sólo para asegurarnos que la necesidad de inmigrar desaparecería (Rawls, 1999: 9), si todas las sociedades se organizasen de acuerdo a una estructura interna liberal o decente. Rawls menciona como causas de la inmigración, la persecución étnica y religiosa, la opresión política, las hambrunas (que él piensa, se pueden prevenir exclusivamente mediante políticas públicas), y la presión del crecimiento de la población (que él piensa, es prevenible mediante políticas públicas). En una sociedad internacional de sociedades bien-ordenadas, estas causas no existirían. De este modo, el "problema" de la inmigración sería eliminado como un problema serio en la utopía realista. 


\section{CUALIFICANDO UN DERECHO A MSF}

Bruce Ackerman (1980) ha argumentado en forma convincente que los argumentos morales aceptables para negar la posibilidad de inmigrar a todos aquellos que aspiran a ello están estrictamente limitados por los principios liberales, ya que de acuerdo a su teoría de neutralidad liberal no podemos afirmar ni el mayor valor de algunos individuos ni de determinados planes de vida para justificar políticas públicas; quedan pocos argumentos disponibles para negar el acceso a todos aquellos que los deseen. En la teoría de Rawls la situación es similar. El derecho a ingreso en una sociedad estaría sujeto, en primer lugar, a las limitaciones reducibles a los mismos principios que la tornan posible. A continuación voy a examinar críticamente algunos argumentos que, de acuerdo a la teoría de Rawls, podrían justificar restringir el derecho a MSF. En mi opinión, ellos no son conclusivos.

\section{La sociedad como una empresa cooperativa}

En el caso de la teoría de Rawls, la sociedad es entendida como una empresa cooperativa que posibilita ventajas mutuas. Cuando imperan las - por Hume definidas- "circunstancias de la justicia" (escasez relativa de recursos y el carácter limitado de la generosidad humana) surge la motivación para establecer un orden jurídico-político que cumpla con ciertas condiciones de tipo normativo. Esta idea de la sociedad está a la base de la premisa metodológica de la teoría, de acuerdo a la cual los individuos permanecen una vida completa dentro de una sociedad determinada. Por una parte, si los individuos pudiesen emigrar de acuerdo a su voluntad, muchos inmigrantes disfrutarían de los frutos de la cooperación social que ellos no produjeron. Por otra parte, si los individuos abandonasen una sociedad de cuyos frutos cooperativos ellos han disfrutado sin haber todavía participado en la producción (como muchos emigrantes jóvenes), ellos faltarían a la obligación de fair play.

La primera crítica no es en mi opinión conclusiva en forma alguna. Inmigrantes que ingresan a una sociedad caracterizada por una alta calidad de vida son tan poco merecedores de estos frutos como todos aquellos que nacen en esa sociedad. Todavía más: normalmente aquellos que nacen en una sociedad disfrutan de los frutos cooperativos por mucho más tiempo que los inmigrantes -la mayoría de los cuales emigra en edades productivas-, antes de comenzar a participar en la producción. Y si damos la oportunidad a todos aquellos que nacen en una sociedad para que se integren a las actividades productivas y consideramos que la ciudadanía o nacionalidad es un elemento contingente y por tanto moralmente arbitrario, ¿en base a qué razones moralmente aceptables podríamos negar esta posibilidad a todos aquellos que se integran a esta empresa cooperativa "desde afuera"?

La segunda crítica es más complicada pero tampoco es conclusiva. No es convincente que la obligación de fair play se extienda hasta el punto de impedir la emigración. La obligación de fair play, que podemos retrotraer a los trabajos de Hart (1955), ha sido utilizada por Rawls en A Theory of Justice. Desde la perspectiva del fair play podemos aclarar por qué en un contexto determinado, en el que determinadas prácticas son efectivas, tenemos determinadas obligaciones. Ella puede explicar también por qué en un contexto 
hipotético tendríamos una determinada obligación. (Lo que la obligación de fair play no puede aclarar es por qué la práctica tiene que continuar existiendo ni por qué la práctica debería existir). El principio de fairness de Rawls se basa en la idea que nosotros debemos contribuir nuestra "parte fair" para así mantener las ventajas que disfrutamos en razón del "esfuerzo cooperativo de otros" (Rawls, 1971:343, también 112). Es evidente que en algún contexto de argumentación hipotético, como la posición original, los individuos estarían de acuerdo con establecer algún tipo de obligación de fair play (Barry, 1995). Esto se debe a que los individuos no quieren ser explotados por free-riders y quieren evitar que muchos servicios públicos no existan (una consecuencia del problema de acción colectiva que surge debido a los free-riders). La pregunta relevante entonces es: ¿estarían los individuos en la posición original de acuerdo con la idea de que el principio de fair-play deba extenderse hasta el punto de impedir la emigración de personas que han disfrutado de determinadas ventajas de la cooperación social sin haber contribuido a su generación?

Rawls mismo no está de acuerdo con que la libertad de emigración pueda ser limitada -aunque por cierto la posibilidad de su realización está sujeta a la voluntad de otras sociedades para aceptar inmigrantes (posibilidad que no está cualificada de acuerdo a principios de justicia). Y si atendemos a cuáles son los estados en el mundo que prohíben la emigración de sus ciudadanos, notamos en cuán desagradable compañía nos encontraríamos (aunque ésta no es evidentemente una argumentación). En mi opinión, una razón para rechazar la restricción de la libertad de emigrar en razón de la obligación de fair play es que, aunque fuese el caso que las ventajas disfrutadas puedan ser moralmente obligantes, al menos en el sentido limitado que se puede dar a una obligación de gratitud (y muchos individuos posiblemente sienten algo similar a esta obligación), no lo son al punto de poder limitar la libertad de los individuos para abandonar una sociedad. Esta última es una libertad básica que se funda, por una parte, en el ideal de la IO para perseguir nuestros planes de vida y, por otra parte, en la relevancia del derecho de salida dentro de la tradición liberal: la renuncia a este derecho implicaría la renuncia al derecho liberal por excelencia que nos ofrece la última protección contra la opresión. La imagen de un Estado como un ente que puede obligar a sus ciudadanos a permanecer bajo su dominio en tanto reparte ventajas, debe ser reelaborada a favor de la imagen de un Estado que compite con otros estados mediante las ventajas y oportunidades ofrecidas para mantener a sus ciudadanos bajo su dominio. Pero incluso si aceptásemos esta extensión de la obligación de fair play, al menos en el caso de los inmigrantes económicos no es evidente que ellos no cumplan con su parte fair en el proceso productivo de sus sociedades de origen, si consideramos las transferencias económicas que suelen ir a la par con la inmigración.

\section{El argumento de orden público}

De acuerdo a Rawls es posible limitar libertades en razón de la libertad misma y todas las libertades dependen de un sistema de orden y seguridad público. De este modo, si debido al derecho a MSF la cantidad de individuos haciendo uso de esta libertad pone en peligro el ejercicio de otras libertades, y esto disminuye el sistema total de libertades, sería posible, tanto en la teoría ideal como en la teoría no-ideal, limitar la inmigración 
en razón del mayor sistema de libertades. Apelando a este argumento es posible limitar el derecho a MSF. Sin embargo, esta limitación debe ser cualificada.

La teoría ideal de Rawls se caracteriza por el cumplimiento perfecto. Esto quiere decir que las condiciones imperantes hacen posible la garantía de los principios de la justicia y que los individuos actúan de acuerdo a estos principios. Sin embargo, es posible imaginar una situación en la que, en razón de las grandes cantidades de individuos que disfrutando de la irrestricta migración cruzan fronteras políticas, en una sociedad determinada se produzca caos y se destruya el orden público que hace posible las libertades, aunque los individuos actúen de acuerdo a las especificaciones institucionales de los principios de la justicia. En este caso sería posible limitar el derecho de los individuos a MSF en pos de las libertades mismas. La razón es que en esta situación de caos y destrucción del orden público todos estarían peor. Y ya que la posición de los individuos representativos peor situados es decisiva en la argumentación en la posición original, los individuos en la posición original querrían evitar una posición en la que ellos estarían peor de lo que es necesario en relación a las libertades básicas. Por lo tanto, ellos aceptarían limitar la MSF en estas circunstancias.

En todo caso, la limitación de la libertad a MSF estaría sujeta a una restricción metodológica importante: Rawls es consciente de que el principio de orden público puede ser interpretado de un modo peligrosamente generoso, y por lo tanto limita su aplicación a casos en los que la tesis acerca de la destrucción del orden público se base en evidencia y modos de razonamiento aceptables para todos (Rawls, 1971: 213). Una posibilidad hipotética de destrucción del orden público no es suficiente. De este modo, en este caso la carga de la prueba estaría en todos aquellos que quieren limitar la inmigración.

\section{El argumento de seguridad nacional}

La teoría de justicia de Rawls es una teoría ideal. Sin embargo, de acuerdo a Rawls ésta nos ofrece guías apropiadas para considerar situaciones no ideales, en las que no se cumple la condición de cumplimiento perfecto señalada en el punto anterior. En el caso de la migración esto permitiría articular razones más fuertes para cualificar un derecho a MSF y sostener un principio más fuerte de soberanía nacional: si los inmigrantes potenciales no están dispuestos a respetar las instituciones liberales que expresan esta concepción de justicia, tenemos en la teoría de Rawls una razón de principio para restringir su ingreso: la garantía de la libertad misma. (También Ackerman (1980) reconoce esta razón como legítima para justificar la restricción). En este caso, el argumento señalado relativo al orden público toma la forma de un argumento de seguridad nacional (compare Carens, 1987). Sin embargo, esta restricción legítima está sujeta a una implementación cuidadosa.

Primero: debe realizarse un examen cuidadoso sobre la disposición de los inmigrantes potenciales para respetar las instituciones liberales, y este examen debe ser realizado en una base individual. El rechazo de una clase de individuos definida por su posible peligrosidad (quizás provienen de sociedades en las que los principios definitorios de una concepción de justicia liberal son ampliamente rechazados, o sostienen creencias religiosas que algunos grupos interpretan de un modo contrario e incompatible a estos 
principios) no está permitido. Aceptar un criterio no individual de selección implica una discriminación no justificada de aquellos que caen en la categoría de selección escogida, pero están dispuestos a respetar las instituciones.

Segundo: el liberalismo afirmado por Rawls es político y no comprehensivo. El liberalismo político aspira a establecer los principios que regulan las instituciones básicas de la sociedad, y sostiene una concepción menos abarcadora de lo político. Sin embargo, esto no implica que los individuos deban guiar su vida de acuerdo a los valores expresados en estas instituciones. Ellos pueden organizar su vida de acuerdo a sus propias concepciones comprehensivas. Para esto pueden utilizar el derecho de asociación garantizado en las sociedades liberales y así organizarse con otros que comparten estas concepciones. De este modo, por ejemplo, sería posible sostener como parte de la propia concepción del bien, que las mujeres no pueden aspirar a las mismas garantías y privilegios que los hombres y correspondientemente otorgar los cargos en la asociación -por ejemplo, una iglesia- en base a la pertenencia sexual. Pero si ellos aceptan el liberalismo político deben reconocer que en el contexto de las instituciones políticas que organizan a la sociedad, tanto hombres como mujeres tienen los mismos derechos. Dicho de otro modo: deben reconocer la ciudadanía liberal igualitaria. Por lo tanto, el examen al que serían sometidos los inmigrantes potenciales no puede referir a sus concepciones del bien, sino que sólo a su disposición a tornar éstas compatibles con la concepción de justicia política liberal imperante.

\section{Circunstancias sumamente desaventajadas}

Rawls es suficientemente claro al afirmar como parte de la teoría no ideal que bajo condiciones sumamente desaventajadas que impiden la realización de las libertades se puede justificar la renuncia a una parte de éstas, si esto nos conduce a largo plazo a una sociedad en la cual las libertades fundamentales pueden ser realizadas. De este modo, si una sociedad es tan desaventajada que ella no puede garantizar las libertades básicas, es posible pensar en una limitación del derecho a MSF, si el acceso de los inmigrantes potenciales impidiese o dificultase el desarrollo de las libertades fundamentales. Esta tesis se puede expresar de un modo extensivo: si fuese el caso que la garantía de un derecho a MSF nos llevase en una sociedad a una situación tan desaventajada que las libertades básicas no pudiesen ser aseguradas, entonces tendríamos una razón legítima para restringir la inmigración. Este argumento es sobre todo relevante en el caso de ciertas sociedades del tercer mundo que-debido a causas geopolíticas-reciben grandes cantidades de inmigrantes. Sin embargo, hay que señalar que éste no es el caso de las sociedades del primer mundo.

\section{El argumento de las libertades políticas}

Se podría argumentar que la aceptación del MSF disminuye las libertades políticas de los ciudadanos en una sociedad liberal democrática: si no se puede controlar el ingreso de inmigrantes, entonces no se pueden escoger ni implementar políticas públicas que modelen la sociedad en la dirección deseada. 
Esta es una tesis ampliamente sostenida. Aquí basta con señalar que, en sentido estricto, el derecho a MSF no limita los derechos políticos de los ciudadanos -por lo menos no lo hace en un sentido diferente a cómo el respeto de derechos liberales fundamentales limita las libertades democráticas-: una sociedad liberal no puede despachar políticas públicas que atenten contra las libertades fundamentales. Si se sostiene-de un modo más debilitado- que los recién llegados no están familiarizados con el funcionamiento de las instituciones democráticas particulares o, incluso, que no dominan el o los idiomas más ampliamente utilizados en el proceso democrático y, por lo tanto, producen interferencias en este proceso, la solución es simplemente establecer plazos y/o exámenes como condición para la adquisición de la ciudadanía y/o los derechos democráticos correspondientes. Pero esto no nos indica que podamos limitar la inmigración.

\section{El empeoramiento de la posición de los peor situados}

Si la posición de los peor situados en una sociedad receptora empeorase en razón del uso que los migrantes hacen de su libertad a inmigración, ¿tendríamos una razón justificada para restringir su ingreso? Este caso no es irrelevante en muchas sociedades de inmigrantes. Ya que la mayor cantidad de inmigrantes en naciones ricas no tienen capacidades especializadas, o su posibilidad de trabajar en sus especialidades se ve minada por exámenes o trabas burocráticos, son muchas veces los trabajadores menos especializados de la sociedad receptora los que ven sus ingresos disminuidos (por otra parte, para los mejor situados esto implica muchas veces una mejora de su posición, ya que pueden adquirir los bienes de consumo a un precio menor-considere, por ejemplo, babysitting u otros servicios). Este es uno de los argumentos más frecuentemente articulados en los medios contra la inmigración. Sin embargo, en el contexto de la teoría de Rawls la prioridad lexicográfica entre el primer y segundo principio que impide sacrificar libertades en pos de ganancias económicas, restringe los argumentos que podemos articular contra el MSF: no podemos apelar al posible empeoramiento de la situación económica de los menos favorecidos en la sociedad receptora para limitar la libertad de todos aquellos que quieren inmigrar a ésta.

Por encima de esto, si nuestro interés efectivamente refiere a la posición de los peor situados, debemos atender a la posición de los peor situados en las sociedades desaventajadas. Y aquí sería posible argumentar que un derecho a MSF mejoraría la posición de los peor situados en estas sociedades al posibilitar su ingreso en otras sociedades menos desaventajadas. Desde luego se podría argumentar contra esta idea que los inmigrantes no son los peor situados en sus sociedades de origen. Los peor situados en estas sociedades no tendrían acceso a los recursos de índole diversa que hacen posible la emigración. Pero cualquiera sea el mérito de esta afirmación, es evidente que una parte considerable de los recursos que los inmigrantes obtienen con sus actividades productivas favorecen, mediante transferencias, a las sociedades de origen y, así, de un modo indirecto, a los peor situados.

Sin embargo, es posible referirse de un modo indirecto a la posición de los peor situados en la sociedad receptora como un dato relevante. Como ya señalé, el argumento para restringir el MSF en razón del orden público es fuerte en el caso de la teoría no ideal. El 
empeoramiento de la posición de los peor situados podría, efectivamente, transformarse en una amenaza a la paz social. En este caso habría razones de tipo pragmáticas -pero no de justicia-para limitar la inmigración. Estas no son razones de justicia, porque las amenazas a la paz social surgen debido a acciones que no son compatibles con los principios de la justicia. En todo caso, las restricciones a la inmigración así justificadas, son mucho más limitadas que las que encontramos hoy en nuestro mundo.

\section{La inmigración no es un fenómeno relevante}

Como vimos, en The Law of Peoples Rawls argumenta que si se cumple la utopía realista y correspondientemente todos los pueblos y sociedades son bien-ordenados, la inmigración no sería un fenómeno relevante (Rawls, 1999: 9). Por lo tanto, no habría ninguna razón para justificar un derecho a inmigración.

Sin embargo esta tesis no es convincente. En la lista de causas que Rawls afirma desaparecerían si el mundo se organizase de acuerdo a su teoría de las relaciones internacionales, falta la mayor causa de inmigración en nuestro mundo: las desigualdades económicas, que tan a menudo van acompañadas por la mala salud y la falta de educación y nutrición características de la pobreza. La teoría de las relaciones internacionales de Rawls no reconoce ningún principio de justicia distributiva global. Su obligación de asistencia (principio 8) aspira a que las sociedades cargadas puedan adquirir los recursos necesarios para organizarse como sociedades bien-ordenadas. Por una parte estos recursos implican sólo en algunas situaciones transferencias económicas, y en muchas otras situaciones implican asistencia de otro tipo - por ejemplo, asesorías que aspiren a modificar la cultura política (Rawls, 1999: 108-110). Por otra parte, el nivel económico que una sociedad debe alcanzar para poder organizarse de un modo bien-ordenado es mínimo. El objetivo que justifica la aplicación del principio de asistencia en cuanto principio de transición es que las sociedades cargadas puedan acceder a las condiciones mínimas requeridas para poder ser sociedades bien ordenadas, y no el honrar algún principio de justicia igualitaria (Rawls, 1999: 118). De este modo, Rawls no tiene nada que ofrecer para contrarrestar la desigualdad económica. Por lo tanto, y en contra de sus pronósticos, la inmigración continuaría existiendo y siendo un elemento de presión en su sociedad internacional (Nussbaum, 2006).

\section{La cultura política de las sociedades}

En The Law of Peoples Rawls comparte explícitamente la tesis de la asimetría defendida por Walzer, y cómo éste afirma que para mantener la cultura política de las sociedades hay que limitar la inmigración. Sin embargo, este argumento no es compatible con la teoría de Rawls.

Walzer argumenta desde una perspectiva comunitarista, de acuerdo a la cual el contexto político cultural es constitutivo del sentido de lo justo. De este modo es la protección de la cultura política de un pueblo, y así de las bases constitutivas de lo justo, lo que justifica limitar el acceso de inmigrantes (Walzer, 1983: 39). Por encima de esto, desde esta perspectiva es discutible que haya obligaciones de justicia que vayan más allá de 
las fronteras que circunscriben estos contextos y que pudiesen implicar, por ejemplo, la obligación de acoger inmigrantes potenciales. Una política de recepción de inmigrantes debe responder a los intereses de la sociedad en cuestión, o expresar preceptos caritativos ampliamente aceptados en ésta, pero no es una obligación articulada en términos de justicia. Esta posición es debilitada exclusivamente en relación a refugiados.

Es correcto que en Thick and Thin Walzer argumenta a favor de una moralidad minimalista de validez general. Sin embargo, las bases de esa moralidad débil (thin) no se encuentran en una teoría moral filosófica sobre la naturaleza humana o la razón, independiente de los contextos culturales particulares: "the moral minimum is not a free-standing morality. It simply designated some reiterated features of particular thick or maximal moralities" (Walzer, 1994: 10). Esto no tiene que ver con principios generales independientes, sino que con el traslaparse de algunas ideas, que se derivan de ricas (thick) moralidades específicas y contextuales. La respuesta al tema de la migración dependería entonces de la pregunta empírica, si los estándares de las culturas se traslapan en ese punto o no. Pero Walzer argumenta a favor de una política extremadamente minimalista: en razón del traslaparse de las moralidades ricas, esclavitud y genocidio imponen obligaciones de justicia, pero no la inmigración.

Teorías comunitaristas están sujetas a una serie de críticas. Aunque yo considero que estas críticas son pertinentes, no me referiré a éstas. Esto se debe a que el mismo Rawls en su teoría de justicia doméstica no comparte estos argumentos. De acuerdo a Rawls, la justificación de los principios de justicia no se deja retrotraer a determinados contextos históricos y sociales, sino que a una decisión tomada en un contexto de imparcialidad. De este modo, si algún argumento relativo a la cultura política de una sociedad es legítimo para imponer restricciones a la inmigración, éste debe referir a la disposición de los inmigrantes potenciales para respetar las instituciones políticas de carácter liberal y democrático de las sociedades de acogida, como ya referí en relación al argumento de seguridad nacional. Si el argumento para limitar la inmigración en razón de la cultura política refiere a la dificultad para integrar a la gran cantidad de inmigrantes en la cultura política, entonces este argumento puede justificar limitar el número de inmigrantes que gradualmente entran a la sociedad receptora de modo tal que, considerando el tiempo necesario para que los nuevos inmigrantes se familiaricen con las instituciones (por cierto con medidas positivas por parte del Estado), la masa crítica necesaria se mantenga estable. Pero no más allá de este punto.

\section{Respeto al carácter de los pueblos}

Quizás Rawls pretende afirmar más de lo que permitiría la independencia normativa de su concepción de justicia. Una interpretación de la teoría de Rawls, que ha ganado popularidad con los escritos posteriores a $A$ Theory of Justice, establece que los principios de la justicia sólo tienen sentido en un contexto en el que los valores liberales correspondientes son ampliamente aceptados. En The Law of Peoples Rawls lleva la posibilidad de esta interpretación a un extremo. Como vimos, Rawls considera que tanto pueblos liberales como SJD son miembros regulares y con los mismos derechos del Derecho de Gentes. Mientras que los 
pueblos liberales se organizan políticamente de acuerdo a una familia de principios de justicia liberales, las SJD se organizan de acuerdo a su propia concepción comprehensiva del bien. Rawls teme que un Derecho de Gentes que requiera como condición necesaria de membresía la afirmación de principios liberales se opondría al valor liberal de la tolerancia. Este valor requiere que reconozcamos no sólo a los pueblos liberales, sino que también a las SJD como miembros regulares del Derecho de Gentes. De este modo, el valor de la tolerancia en el contexto internacional garantizaría la pluralidad de concepciones del bien que definen el carácter de las SJD. Si permitiésemos un derecho a MSF, el resultado sería que este carácter se vería afectado por la gran cantidad de inmigrantes que eventualmente ingresarían a algunas sociedades. El respeto al carácter de los pueblos garantizado por la tolerancia nos debería llevar entonces a restringir la inmigración.

A pesar de que este argumento se puede articular en el contexto del Derecho de Gentes de Rawls, él es totalmente insostenible en relación a los principios básicos en los que se basa su teoría de justicia doméstica. De acuerdo a ésta, los individuos en la posición original rechazarían cualquier principio de tipo perfeccionista. Un principio perfeccionista exigiría que las instituciones sociales se organizasen de un modo tal, que se lograse algún tipo de excelencia humana, sin importar las consecuencias de esta organización institucional en la libertad e igualdad de los individuos. Y la razón de este rechazo es que los individuos en la posición original estarían preocupados de que un principio perfeccionista pudiese implicar que ellos deban renunciar a libertades básicas y así perseguir fines que ellos no consideran valiosos. De igual modo, los individuos en una posición original global no estarían dispuestos a limitar su libertad para así asegurar el carácter de un pueblo, un carácter que quizás en el mundo real ellos no comparten o, todavía más, un carácter que está en contra de sus propias concepciones del bien. Esto no es un peligro abstracto. Como vimos, las SJD se organizan de acuerdo a una concepción del bien. De este modo es posible que esta concepción del bien que impregna el carácter de un pueblo atente contra la igualdad de derechos. No en vano afirma Rawls que las sociedades jerárquicas decentes no conocen el concepto de ciudadanía. Ellas sólo tienen miembros.

\section{Las simpatías mutuas}

Una característica constitutiva de los pueblos son las "simpatías comunes", con las que Mill en Considerations on Representative Government define la idea de nacionalidad. De acuerdo a Rawls, quien en este punto sigue la argumentación de Mill, la unidad de los ciudadanos requiere de estas simpatías. Muchos intérpretes de Mill pretenden haber encontrado en esta idea una premisa para defender programas nacionalistas o nacionalistas liberales, en tanto interpretan a Mill incorrectamente y afirman que estas simpatías requieren una cultura común, a menudo definida mediante un lenguaje y una historia compartida (compare Tamir, 1993; Kymlicka, 1995; Miller, 1995). Esta es una interpretación errónea que ha hecho carrera en la discusión filosófica. En realidad Mill es mucho más cuidadoso que sus intérpretes nacionalistas al definir qué condiciones son requeridas para el surgimiento y mantenimiento de estas simpatías. Él menciona una serie de posibles factores (identidad, raza, origen, lenguaje, religión, geografía) y afirma que ninguno de estos factores es una 
condición necesaria o suficiente. De igual modo, Rawls no refiere a ninguna causa de estas simpatías como suficiente o necesaria. Fundamental en este elemento definitorio de los pueblos es que las simpatías que los miembros de un pueblo sienten por los otros miembros, no las sienten por aquellos que no pertenecen a éste. De este modo sería posible argumentar que un derecho a MSF implicaría la destrucción de las simpatías comunes que posibilitan que los pueblos se mantengan unidos y mantengan en marcha a la sociedad como empresa cooperativa.

Sin embargo, esta argumentación es débil. Como a menudo se observa en la discusión crítica en torno a las teorías nacionalistas liberales, las simpatías comunes en las que en ocasiones estas teorías basan las obligaciones de justicia (social) no son tales. En sociedades mayores, sin relaciones face to face, no encontramos estas simpatías, al menos no en el grado en el que los defensores de estas teorías proponen. (En vez de esto, para utilizar conceptos famosos, tenemos "comunidades imaginadas" (Anderson, 1991)). Por encima de esto, no es evidente que las simpatías comunes, sobre todo en un sentido debilitado, no puedan ser extendidas a inmigrantes que acceden a estas sociedades. Por lo demás, no debemos desatender al hecho que estas simpatías sólo son relevantes porque ellas posibilitan la cooperación social. Aunque fuese el caso, por los demás discutible, que las simpatías comunes fuesen necesarias para definir a un pueblo, entonces este argumento en el mejor de los casos nos ofrecería razones para limitar gradualmente el derecho a MSF de modo tal que el número de inmigrantes no pusiese en peligro la cooperación social que estas simpatías posibilitan.

\section{Fronteras y responsabilidad sobre el territorio}

Quizás el argumento más articulado contra un derecho a MSF que podemos encontrar en The Law of Peoples refiere a la tesis defendida por Rawls acerca de la necesidad de definir responsabilidades de un modo territorial. De acuerdo Rawls, cualquiera sea la arbitrariedad histórica de las fronteras, el rol del gobierno en cuanto agente de los pueblos es asumir responsabilidad sobre su territorio, sobre el crecimiento de la población y la sustentabilidad ecológica (Rawls, 1999: 8, 38-39). Si no hay un agente que asuma la responsabilidad, el valor de la propiedad se tiende a deteriorar. De igual modo que con respecto a la propiedad en general, el rol de las fronteras es establecer una circunscripción de la que los pueblos, mediante sus agentes, son responsables. De acuerdo a Rawls, sostener que un pueblo es responsable de que su territorio lo sostenga a perpetuidad es una expectativa razonable. La premisa afirmada en el caso de la justicia doméstica, que debemos entender a los ciudadanos de estas sociedades como miembros a perpetuidad, refiere directamente al rol de las fronteras como delimitadoras de la responsabilidad. Para Rawls la tesis de perpetuidad es central: los pueblos deben reconocer que ellos no pueden compensar sus malas políticas de crecimiento poblacional o sus malas políticas medioambientales mediante la conquista de nuevos territorios o emigrando al territorio de otros pueblos sin el consentimiento de éstos.

El argumento es fuerte porque se basa en (a) una analogía entre individuos y pueblos, y (b) en una concepción de responsabilidad que encuentra amplia aceptación en el mundo 
liberal igualitario: se es responsable de las propias decisiones y por tanto de los costos vinculados con éstas. Sin embargo, es el reverso de este argumento el que le otorga plausibilidad: hay factores, de los que no somos responsables y, por lo tanto, no debemos cargar con todos los costos vinculados (compare Dworkin, 1981, 2000; yo he discutido esta tesis en 2007). A continuación examinaré este argumento.

Como ya examinamos, de acuerdo a la teoría de justicia doméstica de Rawls, las consecuencias de los factores morales arbitrarios deben ser corregidas de acuerdo a principios de justicia. De este modo no somos responsables por éstos y no debemos cargar con todos los costos vinculados. En la analogía realizada por Rawls en el caso internacional tendríamos que preguntar ¿de qué factores los pueblos no son responsables y correspondientemente con qué costos no deben cargar? Sin embargo, en el Derecho de Gentes de Rawls los pueblos son responsables de todos los costos (Moellendorf, 2002). Esto torna el argumento poco plausible. El argumento relativo a la responsabilidad de los pueblos sólo sería convincente si tuviese lugar algún tipo de compensación por situaciones iniciales desaventajadas y no merecidas. Teorías como las de Beitz, con su principio de distribución de recursos y su principio de distribución global, o como la de Pogge, con su dividendo de recursos general, podrían realizar esta tarea. Pero Rawls rechaza cualquier principio de distribución global. Rawls se refiere aquí expresamente a la teoría de Beitz y de Pogge (Rawls, 1999: 115 y siguientes). De este modo, y en tanto no haya tenido lugar una transferencia de recursos que compense por situaciones no merecidas, el rechazo de Rawls de un derecho a MSF no sería justificable.

El argumento de Rawls a favor de la responsabilidad total de los pueblos se deja retrotraer a su afirmación (para cuyo sustento él refiere exclusivamente al libro de David Landes: The Wealth and Poverty of Nations (Rawls, 1999: 117, nota 51)) que los únicos factores que explican el éxito o fracaso de los pueblos se encuentran en su cultura política (Rawls, 1999: 108). Pero aunque esta tesis es quizás en forma general correcta, ella no se mantiene sin fuertes cualificaciones. El éxito y fracaso de los pueblos se relaciona de un modo considerable con las externalidades producidas por las acciones de terceros en relación a un sistema de prácticas establecidas (compare Pogge, 2002: 139-140). De este modo, sin atender a estas externalidades y prácticas (modelos de consumo, reglas de comercio internacional, leyes de patentes, etc.), no se puede afirmar la tesis de la perpetuidad y correspondientemente justificar el rechazo de un derecho a MSF. Esto también se aplica a los resultados surgidos en un proceso histórico. Como Benhabib argumenta, es sorprendente que Rawls no preste ninguna atención a la historia (Benhabib, 2004: 100).

Pero aunque en razón de principios de justicia global haya tenido lugar una compensación originaria y se atienda a las externalidades, la tesis de Rawls relativa a la perpetuidad no se sostiene. El problema es que la analogía entre individuos y pueblos propuesta por Rawls es insostenible. La analogía de individuos que están en una mala situación debido a las malas decisiones de sus gobiernos, no es la posición de un individuo que está en una mala situación debido a sus propias malas decisiones, sino que la posición de un niño que está en una mala posición debido a las malas decisiones de sus padres. Y como Beitz afirma: "Consideraciones acerca de la responsabilidad no disminuyen el peso de la consideración 
ética acerca del bienestar de los descendientes" (Beitz, 1999: 527). De este modo no sería posible limitar el derecho a inmigrar de todos aquellos que están en una mala posición debido a las malas decisiones de sus gobernantes. El que malos gobiernos puedan destruir la capacidad de un territorio para sostener a su pueblo a perpetuidad, no implica que se deba limitar la libertad de los individuos que sufren bajo esas malas políticas para buscar mejores oportunidades de vida cruzando fronteras. Desde una perspectiva de justicia global es válido probablemente lo contrario. Esto no es irrelevante cuando notamos que las SJD no son sociedades democráticas. Esto torna la analogía entre individuos y pueblos en el argumento relativo a la responsabilidad todavía más dudosa.

\section{Autodeterminación e intromisión}

Un último argumento contra un derecho a MSF que examinaré se retrotrae a una premisa fundamental de The Law of Peoples: el derecho a autodeterminación de los pueblos. En su teoría Rawls le otorga a la autodeterminación de los pueblos un valor central. El principio (4) refiere expresamente a ésta. Y los cinco primeros principios, que se dejan reducir a la idea de la igualdad fundamental de los pueblos, refieren al derecho de los pueblos a reglar sus propios asuntos. Esto no debe ser malentendido. Rawls no sostiene una concepción absoluta de autodeterminación o soberanía. Su teoría del derecho de pueblos no es realista, en el sentido técnico de referir exclusivamente a los intereses de los estados y caracterizar el contexto internacional como un tipo de estado de naturaleza. Su teoría corresponde más bien a una concepción normativa acerca de las relaciones internacionales. Una diferencia fundamental entre pueblos y estados, en la cual Rawls basa su decisión de esbozar un derecho de pueblos y no una teoría de la relaciones entre estados, es que de acuerdo al entendimiento de Rawls los pueblos, a diferencia de los estados, tienen un carácter moral. Este carácter se expresa en que, a diferencia de los estados que actúan con una base exclusivamente racional en tanto persiguen sus intereses, los pueblos cualifican la racionalidad en la consecución de sus fines mediante la razonabilidad. La idea de razonabilidad, que en la teoría de Rawls nos lleva a la idea de la razón publica, no está carente de dificultades. Sin embargo, de un modo general y basándonos en la interpretación que Rawls realiza en Liberalismo Político del concepto de razonabilidad desarrollado por Scanlon (1998), podemos decir que la razonabilidad refiere a la motivación moral de querer justificar nuestras acciones frente a todos aquellos que sufren sus consecuencias, mediante razones que nosotros podemos esperar que ellos puedan razonablemente aceptar. La idea a la base de la razonabilidad refiere entonces a la necesidad moral de justificación de nuestras acciones.

En la teoría de justicia doméstica la razonabilidad se expresa en el reconocimiento de las demandas del liberalismo político, independientemente del carácter moral, religioso o filosófico de las doctrinas comprehensivas que sostengamos. Si las doctrinas que sostenemos reconocen las demandas del liberalismo en cuanto doctrina política, nuestras doctrinas son razonables y no hay ninguna razón para no ser tolerantes con respecto a ellas. La justificación de la tolerancia es así, en la teoría de justicia doméstica de Rawls, independiente, en el sentido que ella refiere a la falta de razones para no tolerar doctrinas que no son irrazonables. En el contexto del derecho de pueblos la razonabilidad es 
definida de un modo diametralmente distinto: la razonabilidad de los pueblos no refiere al reconocimiento que éstos efectúen del liberalismo en cuanto doctrina política, sino que al reconocimiento de los principios definitorios del Derecho de Gentes propuesto por Rawls. Si los pueblos reconocen el Derecho de Gentes de Rawls, entonces son razonables y no tenemos razones para no tolerarlos.

Esta diferencia en la definición de la razonabilidad en el contexto doméstico y en el contexto internacional no está carente de consecuencias: al otorgarle a ciertas sociedades que no reconocen el liberalismo en cuanto doctrina política -las SJD- el estatus de miembros regulares y con los mismos derechos del Derecho de Gentes, Rawls reconoce que sociedades que se organizan en forma política de acuerdo a sus doctrinas morales, religiosas o filosóficas son razonables. Pero esto no tiene sentido. Como vimos, la razonabilidad se define mediante el reconocimiento del liberalismo político. Si siguiésemos en forma analógica el argumento que Rawls articula en el contexto del Derecho de Gentes ahora al nivel de la justicia doméstica, tendríamos que afirmar que las doctrinas comprehensivas que no reconocen las demandas del liberalismo en cuanto doctrina política, son doctrinas razonables, lo que evidentemente no tiene sentido. Se podría argumentar que "razonabilidad" no tiene por qué ser definida de igual modo en el contexto doméstico y en el contexto internacional. Quizás haya buenos argumentos para sostener una tesis como ésta. En todo caso, Rawls no ofrece ningún argumento para justificar este desfase en la definición de la razonabilidad en el contexto doméstico y en el contexto internacional.

Esta discusión es relevante cuando examinamos la posibilidad de justificar un derecho a MSF dentro de un contexto de argumentación rawlsiano. Desde la perspectiva del Derecho de Gentes de Rawls, se podría argumentar que un derecho a MSF implicaría una intervención inaceptable en los asuntos internos de los pueblos. SJD no son sociedades liberales, y por lo tanto no hay ninguna razón para sostener que ellas deben aceptar un derecho a MSF, que por cierto es expresión de premisas liberales. Y si de acuerdo a la concepción de razonabilidad utilizada por Rawls podemos decir que estas sociedades son razonables, no habría ninguna razón para no tolerarlas. Tolerancia es en el Derecho de Gentes de Rawls un concepto con pretensiones mayores. Tolerancia, afirma Rawls, es una forma de respeto que excluye cualquier tipo de intromisión. Esto refiere no sólo a intervenciones armadas u económicas, sino que refiere incluso a cualquier tipo de incentivos y todavía más: de crítica. Si las SJD son miembros regulares con los mismos derechos de la sociedad de pueblos, no tenemos ninguna razón que nos permita intervenir, aunque ellas sean, por ejemplo, discriminatorias, si es que esta discriminación se retrotrae a su concepción del bien. De este modo no habría ninguna razón para obligar o incentivar a las sociedades no liberales que Rawls denomina SJD, para que acepten un derecho a MSF. En estricto sentido, no habría ni siquiera razones para criticarlas por no hacerlo.

Por cierto es posible argumentar que la interpretación cosmopolita de Rawls no permite esta extensión de la tolerancia en el contexto internacional. Desde una perspectiva liberal cosmopolita no habría razones de justicia para, por lo menos, no criticar a las sociedades que no respetan valores liberales, y tampoco para no tratar de promover desarrollos liberales mediante incentivos (un asunto completamente diferente refiere a las posibles razones 
pragmáticas para no hacerlo). Pero para el efecto de la argumentación actual voy a dar por sentado de un modo hipotético que en el contexto del Derecho de Gentes habría buenas razones para sostener esta concepción amplia de tolerancia, y correspondientemente de no-intervención. Si este fuese el caso: ¿tenemos razones para rechazar un derecho a MSF? Una respuesta positiva a esta pregunta sería incorrecta. La razón es que, aunque desde esta perspectiva no tengamos razones válidas para hacer vinculante la aceptación de un derecho a MSF por parte de las SJD, y tampoco para promover mediante incentivos que ellas acepten este derecho, no hay ninguna razón para que las sociedades liberales no acepten este derecho. Sociedades liberales deberían reconocer un derecho a MSF, aunque otras sociedades, que no son liberales, no lo reconozcan. Si este argumento es correcto, entonces tenemos razones, aun en un mundo como el nuestro que no está sólo compuesto por pueblos liberales, para argumentar que al menos las sociedades liberales deben reconocer un derecho a MSF.

\section{CONCLUSIÓN}

En este texto hemos visto que la teoría de la justicia de Rawls desconoce el fenómeno de la migración. En The Law of Peoples Rawls acepta la tesis de la asimetría y aprueba incluso los argumentos articulados por Walzer relativos a la limitación de la inmigración como un medio para proteger la cultura política de la sociedad (Rawls, 1999: 39, nota 48). Sin embargo, la aceptación de la tesis de la asimetría no es consistente con la premisa básica de su teoría que refiere a la IO. Por una parte, he argumentado que una interpretación cosmopolita de la teoría de Rawls permite articular argumentos convincentes a favor de un derecho a MSF. Por otra, he argumentado que los argumentos que se pueden articular desde la perspectiva de la teoría de justicia doméstica de Rawls y desde la perspectiva de su Derecho de Gentes contra un derecho a MSF no son concluyentes. Sin embargo, estos argumentos nos ofrecen razones para cualificar un derecho a MSF. Las razones más importantes para justificar esta cualificación refieren al orden público y a la seguridad nacional, necesarios para la existencia de las libertades. Otras razones relevantes refieren al grado máximo de integración de inmigrantes que una sociedad puede aceptar medido en relación al mantenimiento de su cultura política, y el mantenimiento de las simpatías mutuas necesarias para mantener la empresa cooperativa en marcha. Un tercer tipo de razones, que refiere a la autodeterminación de los pueblos y a la no-intervención, sólo podría eventualmente justificar el rechazo por parte de las sociedades no liberales del derecho a MSF, pero no el rechazo por parte de los pueblos liberales. Una interpretación cosmopolita de Rawls debería ser mucho menos crítica con respecto a un mundo en el cual el MSF es efectivo. 


\section{REFERENCIAS}

Ackerman, Bruce. 1980. Social Justice in the Liberal State. New Haven, London: Yale University Press. Anderson, Benedict. 1991 (1983). Imagined Communities. London, New York: Verso.

Barry, Brian. 1974. A Liberal Theory of Justice. Oxford: Oxford University Press.

Barry, Brian. 1989. Theories of Justice. Berkeley, Los Angeles: University of California Press.

Barry, Brian. 1995. Justice as Impartiality. Oxford: Clarendon Press.

Beitz, Charles. 1979. Political Theory and International Relations. Princeton, New Jersey: Princeton University Press.

Beitz, Charles. 1999. "Social and Cosmopolitan Liberalism". International Affairs 75(3): 515-529.

Beitz, Charles. 2000. "Rawls's Law of Peoples". Ethics 110(4): 669-696.

Benhabib, Seyla. 2004. The Rights of Others. Cambridge: Cambridge University Press.

Buchanan, Allen. 2000. "Rawls's Law of Peoples: Rules for a Vanished Westphalian World". Ethics 110(4): 697-721.

Caney, Simon. 2001a. "Cosmopolitan Justice and Equalizing Opportunities". Metaphilosophy 32(1/2): 113-134.

Caney, Simon. 2001b. "International Distributive Justice". Political Studies 49(5): 974-997.

Carens, Joseph. 1987. “Aliens and Citizens. The Case of Open Borders”. Review of Politics 49 (2): 251-273.

Carens, Joseph. 1992. "Migration and Morality: A liberal Egalitarian Perspective". En Free Movement, editado por B. Barry y R. Goodin University Park: Pennsylvania State University Press, 25-47.

Cavanagh, Matt. 2002. Against Equality of Opportunity. Oxford: Clarendon Press.

Dummett, Ann. 1992. "The Transnational Migration of People Seen From Within a Natural Law Tradition". En Free Movement, editado por B. Barry y R. Goodin. University Park: Pennsylvania State University Press, 169-180.

Dworkin, Ronald. 1981. "Equality of Resources". Philosophy and Public Affairs 10(4): 283-345.

Dworkin, Ronald. 2000. Sovereign Virtue. Cambridge, Massachusetts: Harvard University Press.

Epstein, Richard. 1992. Forbidden Grounds. Cambridge, Massachusetts: Harvard University Press.

Gray, John. 2000. Two Faces of Liberalism. Cambridge: Polity Press.

Hart, Herbert. 1955. “Are there Any Natural Rights?". The Philosophical Review 64 (2): 175-191.

Höffe, Otfried. 1999. Demokratie im Zeitalter der Globalisierung. München: C.H. Beck.

Kymlicka, Will. 1995. Multicultural Citizenship. Oxford: Clarendon Press.

Landes, David. 1998. The Wealth and Poverty of Nations. New York: W. W. Norton.

Loewe, Daniel. 2007. “Teorías de justicia igualitaria y derechos culturales diferenciados". Isegoría 36: 275-302.

Martin, Rex y David Reidy. 2006. Rawls's Law of Peoples. A Realistic Utopia? Oxford: Blackwell Publishing.

Miller, David. 1995. On Nationality. Oxford: Clarendon Press.

Moellendorf, Darrel. 2002. Cosmopolitan Justice. Oxford: Westview Press.

Nussbaum, Martha. 2006. Frontiers of Justice. Cambridge, Massachusetts: Harvard University Press.

Pogge, Thomas. 1989. Realizing Rawls. Ithaca y London: Cornell University Press.

Pogge, Thomas. 1994. "An Egalitarian Law of Peoples". Philosophy and Public Affairs 23(3): 195-224.

Pogge, Thomas. 2002. World Poverty and Human Rights. Cambridge: Polity Press.

Rawls, John. 1971. A Theory of Justice. Cambridge, Massachusetts: Harvard University Press.

Rawls, John. 1993. Political Liberalism. New York: Columbia University Press.

Rawls, John. 1993. "The Law of Peoples". En On Human Rights, editado por St. Shute y S. Hurley. New York: Basic Books, 41-82.

Rawls, John. 1999. The Law of Peoples with "The Idea of Public Reason Revisited". Cambridge, Massachusetts: Harvard University Press.

Roemer, John. 2000. "Equality of Opportunity". En Meritocracy and Economic Inequality, editado por K. Arrow, S. Bowles y S. Durlauf. Oxford, New York: Oxford University Press, 17-32.

Rorty, Richard. 1998. Achieving Our Country. Cambridge, Massachusetts: Harvard University Press. 
Rowlands, Mark. 1998. Animal Rights. New York: Palgrave Macmillan.

Rowlands, Mark. 2002. Animals like Us. New York: Verso.

Scanlon, Thomas. 1998. What We Owe to Each Other. Cambridge, Massachusetts: Harvard University Press.

Tamir, Yael. 1993. Liberal Nationalism. Princeton: Princeton University Press.

Tan, Kok-Chor. 2000. Toleration, Diversity, and Global Justice. College Park, PA: Pennsylvania State University Press.

Tan, Kok-Chor. 2004. Justice without Borders. Cambridge: Cambridge University Press.

Tasioulas, John. 2002. "From Utopia to Kazanistan: John Rawls and the Law of Peoples". Oxford Journal of Legal Studies 22(2): 367-396.

Vitale, Ermanno. 2004. Ius Migrandi. Torino: Bollati Boringhieri.

Walzer, Michael. 1984. Spheres of Justice. New York: Basic Books.

Walzer, Michael. 1996. Thick and Thin. Notre Dame: University of Notre Dame Press.

Daniel Loewe es doctorado con summa cum laude en filosofía en la Universidad de Tübingen, Alemania (2002), y licenciado en filosofía en la Pontificia Universidad Católica de Chile (1995). Ha desarrollado una investigación de Postdoctorado en Oxford y numerosas estadías como Profesor invitado en variadas universidades. Actualmente se desempeña como Profesor Asistente en el Seminario de Filosofía de la Universidad Tübingen, donde desarrolla un proyecto de investigación sobre ética del medio ambiente. Ha publicado numerosos artículos en revistas internacionales.

(dloewe@hotmail.com) 